\title{
Incidence, Predictors, and Adverse Outcomes of Extubation Failure in Young Children with Isolated Traumatic Brain Injury: A Prospective Observational Study
}

\author{
Amarjyoti Hazarika ${ }^{1}$ Aakriti Gupta ${ }^{1}$ Kajal Jain
${ }^{1}$ Department of Anaesthesia and Intensive Care, Postgraduate \\ Institute of Medical Education and Research, Chandigarh, India
}

\begin{abstract}
Address for correspondence Aakriti Gupta, MD, Department of Anaesthesia and Intensive Care, Nehru Hospital, Postgraduate Institute of Medical Education and Research, 4th Floor, Sector 12, Chandigarh 160012, India (e-mail: aakriti1988.ag@gmail.com).
\end{abstract}

\begin{abstract}
Keywords

- pediatric

- isolated head injury

- predictors

- extubation failure

Background Mechanical ventilation is a life-saving mainstay of therapy in pediatric patients with isolated traumatic brain injury (iTBI). Because of the numerous complications and side effects associated with tracheal intubation, it is prudent to remove it as early as possible. Extubation failure and reintubation, however, are also associated with significant risks. Till date, there has been no comprehensive study on extubation failure in pediatric patients less than 5 years with iTBI.

Methods A prospective observational study was conducted in the trauma intensive care unit (TICU) of a tertiary care center. All the children with iTBI, aged 0 to 5 years, on mechanical ventilation for more than 24 hours, admitted to the TICU were included. Extubation failure was defined as the need for reintubation occurring within 24 hours of extubation. Only the first attempt at extubation was included in the analysis.

Results Pre-extubation $\mathrm{paO}_{2} / \mathrm{FiO}_{2}$ ratio $<310 \mathrm{~mm} \mathrm{Hg}$ is a predictor for extubation failure. Mean base deficit postextubation were found to be $2 \pm 0.9$ and $-0.2 \pm 1$ $(p=0.00)$ between success and failure groups, respectively. Similarly, postextubation systolic blood pressure was also high in the failure group than in the success group (113.8 \pm 10.4 vs. $100.5 \pm 7.4 ; p=0.00)$.

Conclusions The incidence of first attempt extubation failure was $62.5 \%$. Lower values of pre-extubation $\mathrm{paO}_{2} / \mathrm{FiO}_{2}$ ratio (ratio $<310 \mathrm{~mm} \mathrm{Hg}$ ) are a predictor for extubation failure. Developing predictive tools and optimizing extubation decisions lead to timely identification of patients at elevated risk of extubation failure.
\end{abstract}

\section{Introduction}

Isolated traumatic brain injury (iTBI) in children is a major cause of death, disability, and economic cost to our society. It affects more than 3 million children worldwide every year. ${ }^{1}$ Mechanical ventilation is a life-saving mainstay of therapy in pediatric patients with iTBI. Patients with iTBI having Glasgow Coma Score (GCS) less than 8 require definitive airway protection because they are at risk of pulmonary aspiration or compromised respiratory drive and function. Because of the numerous complications and side effects associated with this therapy, ${ }^{2,3}$ it is prudent to remove the patient from this mode of support as early in the clinical course as possible. Extubation failure and reintubation, however, are also associated with significant risks, including an increased incidence of pneumonia, prolonged stay in the intensive
Published online

February 23, 2020
DOI https://doi.org/ 10.1055/s-0040-1701799 ISSN 2348-0548.
(C2020. Indian Society of Neuroanaesthesiology and Critical Care. This is an open access article published by Thieme under the terms of the Creative Commons Attribution-NonDerivative-NonCommercial-License, permitting copying and reproduction so long as the original work is given appropriate credit. Contents may not be used for commercial purposes, or adapted, remixed, transformed or built upon. (https://creativecommons.org/licenses/by-nc-nd/4.0/).

Thieme Medical and Scientific Publishers Pvt. Ltd. A-12, 2nd Floor, Sector 2, Noida-201301 UP, India 
care unit (ICU), and increased mortality. ${ }^{4-6}$ Extubation failure rates in general pediatric ICUs (PICUs) range from 2.7 to $22 \%{ }^{6}$ However, studies on adult TBI population, cited the figure ranging from 16 to $40 \%$ based on different criteria of extubation. ${ }^{7,8}$ Patient features associated with extubation failure in PICU include a spectrum of causes ranging from a duration of intubation $>72$ hours, age $<24$ months, dysgenetic condition, syndromic children, chronic respiratory disorder, chronic neurologic condition, medical or surgical airway condition, chronic noninvasive positive pressure ventilation, the need to replace the endotracheal tube (ETT) on admission to the ICU, use of racemic epinephrine, steroids, helium-oxygen therapy (heliox), or use of noninvasive positive pressure ventilation within 24 hours of extubation. ${ }^{6}$

To date, there has been no comprehensive study on extubation failure in pediatric patients less than 5 years with iTBI. In our study, we attempted to find the incidence, predictors, and outcomes of extubation failure in this group of patients.

\section{Methods}

A prospective observational study was conducted in the trauma ICU of a tertiary care center after obtaining approval of the institutional ethics committee and written informed consent from the parents/guardians. The trial was registered in the Central Trial Registry of India (CTRI/2017/03/008191). All children with isolated traumatic head injury, aged 0 to 5 years, on mechanical ventilation for more than 24 hours, admitted to the trauma ICU over a period of 24 months (from July 2017 to June 2019) were enrolled in the study. Children with known underlying systemic disease, previously known neurological disorder, chronic respiratory disease, syndromic children, unplanned extubation, and children tracheostomized without an extubation trial were excluded from the study.

Extubation was defined as planned removal of the ETT. Extubation failure was defined as the need for reintubation occurring within 24 hours of extubation. Only the first attempt at extubation was included in the analysis. This being an observational study, the decision to extubate or reintubate was taken by the ICU consultant in-charge based on their clinical judgment and standard weaning/extubation protocols $^{9}$ (- Table $\mathbf{1}$ ).

The investigator observed and recorded the following parameters:

- Demographic variables

- GCS on admission

- ICU admission operative status-postoperative/ nonoperative.

- The site of ETT placement-within/outside the study hospital

- Type of ETT-cuffed/uncuffed

- Computed tomography head findings

- Quality of ETT secretions-thick/thin at the time of extubation

- Arterial blood gas (ABG) before and after extubation with parameters of $\mathrm{paO}_{2}, \mathrm{paCO}_{2}, \mathrm{paO}_{2} / \mathrm{FiO}_{2}$, base deficit, and lactate level
- Hemodynamic parameters such as heart rate and systolic blood pressure (SBP) at the time of ABG analysis (before and after extubation)

- Serum electrolytes (sodium and potassium levels), albumin level, and hemoglobin levels

- Use of pre-extubation steroid (injectable dexamethasone)

- Presence of symptoms/signs of upper airway obstruction (UAO) following extubation

- Use of postextubation adrenaline nebulization

- Number of sedation days

- Number of days on mechanical ventilation

- Length of ICU stay

- Number of extubation failures

- Whether the patient is tracheostomized or not

- Mortality

All patients were sedated with a combination of midazolam and fentanyl at the discretion of the intensivist. Adrenaline nebulization after extubation was used in patients who had signs of UAO.

\section{Statistical Analysis}

Statistical analysis was performed on subjects admitted during the 24 months of enrollment period. For normally distributed data, independent $t$-test was used. Mann-Whitney $U$-test was used for statistical analysis of skewed continuous variables. Categorical variables were compared using the chisquare test or Fisher's exact test. The extubation failure rate was defined as the number of patients who failed planned extubation at first attempt divided by the total study population. To analyze the predictors of extubation failure, logistic regression analysis was performed. A $p$-value of $<0.05$ was considered statistically significant.

Table 1 Weaning and extubation criteria followed for the study

\begin{tabular}{|c|}
\hline Weaning criteria \\
\hline $\begin{array}{l}\text { Adequate oxygenation (e.g., } \mathrm{PaO}_{2} / \mathrm{FIO}_{2}>200 \mathrm{~mm} \mathrm{Hg} \text { ) on low } \\
\text { PEEP }\left(5-8 \mathrm{~cm} \mathrm{H}_{2} \mathrm{O}\right) \text { and } \mathrm{pH}>7.35 \text {. Hemodynamic stability: no } \\
\text { clinically important hypotension (no vasopressors) }\end{array}$ \\
\hline Capability to initiate an inspiratory effort \\
\hline Glasgow Coma Scale $\geq 10$, i.e., $\mathrm{E}_{4} \mathrm{~V}_{\mathrm{t}} \mathrm{M}_{6}$ \\
\hline Adequate cough reflex \\
\hline The ability of patient to protect the airway \\
\hline Spontaneous breathing trial (SBT) tolerance lasting 30-120 min \\
\hline $\begin{array}{l}\text { After passing the SBT, artificial airway removal will be based on } \\
\text { an assessment of airway patency }\end{array}$ \\
\hline $\begin{array}{l}\text { Audible leak (to the ear, not the stethoscope) heard at }<25 \mathrm{~cm} \\
\mathrm{H}_{2} \mathrm{O} \text { in a patient with the head in the neutral position }\end{array}$ \\
\hline Extubation readiness criteria on T-piece \\
\hline $\begin{array}{l}\text { Clinical criteria: Absence of diaphoresis, nasal flaring, increase } \\
\text { respiratory effort, tachycardia (increase in HR > } 140 \text { bpm), } \\
\text { hypotension }\end{array}$ \\
\hline $\begin{array}{l}\text { Laboratory criteria: Absence in a decrease of arterial } \mathrm{pH}<7.32 \text { or } \\
\text { decline in arterial } \mathrm{pH}>0.07\end{array}$ \\
\hline $\mathrm{PaO}_{2}<60 \mathrm{~mm} \mathrm{Hg}$ with an $\mathrm{FiO}_{2}>0.40\left(\mathrm{P} / \mathrm{FO}_{2}\right.$ ratio $\left.<150\right) \mathrm{SpO}_{2}>95 \%$ \\
\hline
\end{tabular}

Abbreviations: $\mathrm{HR}$, heart rate; $\mathrm{PEEP}$, positive end-expiratory pressure. 


\section{Results}

A total of 74 children with head injury were admitted in the trauma center intensive care of our tertiary care center over 24 months. Out of these, 18 patients were excluded from the study as they were tracheostomized without receiving an extubation trial. - Fig. 1 shows the flowchart of patients' inclusion in the study. Fifty-six patients were included in the study, out of which $21(37.5 \%)$ patients were successfully extubated, while the other 35 (62.5\%) patients failed the extubation trial. The baseline characteristics of the two groups were comparable (-Table 2 ).

Fall was the most common mode of injury (78.9\%; $n=44)$. Sixteen $(77 \%)$ children in the extubation success group and $35(100 \%)$ children in the extubation failure group were received in an intubated state from outside the hospital. The mean admission GCS between extubation success and extubation failure were comparable ( $4.8 \pm 2.9$ vs. $5.5 \pm 1.8$; $p=0.26$ ). The neurologic injuries in the two groups were similar and included cases of cerebral infarct, extradural hemorrhage, subdural hemorrhage, skull fracture, diffuse axonal injury, cerebral edema, and cerebral contusion.
The parameters observed before and after extubation between the two groups were compared. On univariate analysis, the pre-extubation partial pressure of arterial oxygen $\left(\mathrm{PaO}_{2}\right)$ value and low partial pressure of arterial oxygen/ fraction of inspired oxygen $\left(\mathrm{PaO}_{2} / \mathrm{FiO}_{2}\right)$ ratios in the extubation failure group and postextubation mean base excess and SBP values in the same group were found to be significant (-Tables 3 and 4 ).

However, on multivariate analysis pre-extubation $\mathrm{PaO}_{2} / \mathrm{FiO}_{2}$ ratio in the extubation group was found to be a predictor of extubation failure with a cutoff value of less than $310 \mathrm{~mm} \mathrm{Hg}$ ( $p=0.025,95 \%$ confidence interval: $1.5-11.6)$.

The use of a cuffed versus uncuffed ETT and the nature of endotracheal secretions did not have statistical significance between the two groups with a $p$-value of 1.0 and 0.57 , respectively. Pre-extubation administration of steroids also did not have a significant impact on the success of extubation $(p=1.0)$.

Four (19.04\%) patients in the extubation success group and 12 (34.2\%) patients in the extubation failure group manifested signs of UAO after extubation. The use of

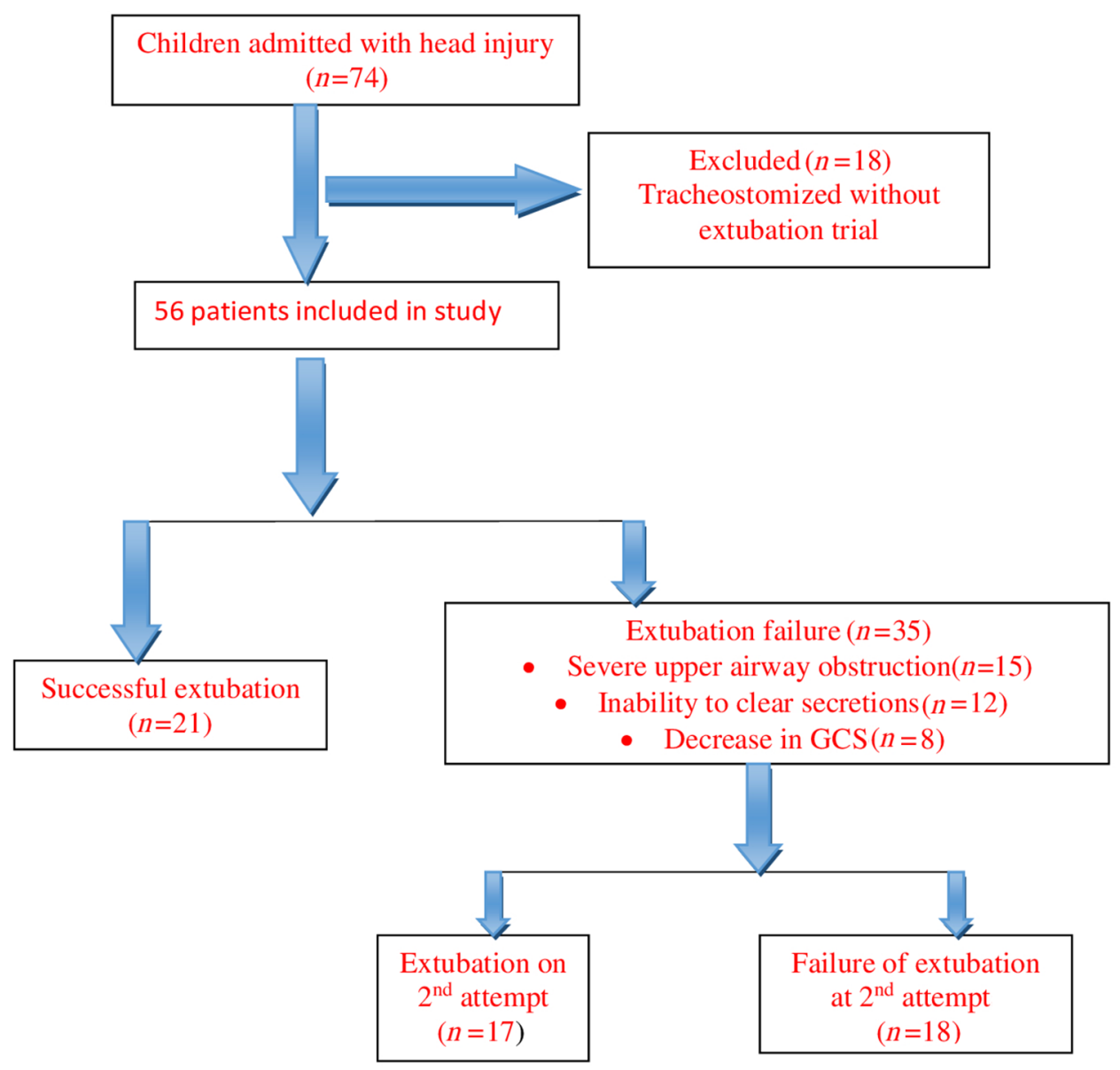

Tracheostomized $(n=4)$

Fig. 1 Flowchart of patients' inclusion in the study. 
Table 2 Baseline characteristics of the studied children

\begin{tabular}{|c|c|c|c|}
\hline & $\begin{array}{l}\text { Extubation } \\
\text { success } \\
(n=21)\end{array}$ & $\begin{array}{l}\text { Extubation } \\
\text { failure } \\
(n=35)\end{array}$ & $p$-Value \\
\hline Age (y) & $2.8 \pm 3.4$ & $4.3 \pm 2.5$ & 0.06 \\
\hline $\begin{array}{l}\text { Gender } \\
\text { (male:female) }\end{array}$ & $16: 5$ & $22: 13$ & 0.38 \\
\hline Mode of injury: Fall & 18 & 30 & \multirow{3}{*}{0.68} \\
\hline RTA & 2 & 5 & \\
\hline Assault & 1 & 0 & \\
\hline Admission GCS & $4.8 \pm 2.9$ & $5.5 \pm 1.8$ & 0.26 \\
\hline Postoperative & 2 & 6 & \multirow{2}{*}{0.69} \\
\hline Nonoperative & 19 & 29 & \\
\hline \multicolumn{4}{|l|}{ Intubation } \\
\hline Hospital & 6 & 8 & \multirow{2}{*}{0.75} \\
\hline Outside & 15 & 27 & \\
\hline \multicolumn{4}{|l|}{ Endotracheal tube } \\
\hline Cuffed & 4 & 6 & \multirow{2}{*}{1.0} \\
\hline Uncuffed & 17 & 29 & \\
\hline \multicolumn{4}{|l|}{ CT head findings: } \\
\hline Infarct & 5 & 10 & \multirow{7}{*}{0.25} \\
\hline $\mathrm{EDH}$ & 4 & 5 & \\
\hline SDH & 1 & 2 & \\
\hline Fracture & 8 & 13 & \\
\hline DAI & 2 & 7 & \\
\hline Edema & 11 & 4 & \\
\hline Contusion & 5 & 12 & \\
\hline \multicolumn{4}{|l|}{ Nature of secretions } \\
\hline Thick & 11 & 22 & \multirow{2}{*}{0.57} \\
\hline Thin & 10 & 13 & \\
\hline
\end{tabular}

Abbreviations: $\mathrm{CT}$, computerized tomography; DAI, diffuse axonal injury; EDH, extradural hemorrhage; GCS, Glasgow Coma Score; RTA, road traffic accident; SDH, subdural hemorrhage.

Note: Values are expressed as mean (standard deviation [SD]) or number of patients.

${ }^{\mathrm{a}} \mathrm{A}$ single patient may have more than one $\mathrm{CT}$ diagnosis.

postextubation adrenaline nebulization failed to significantly impact the success of extubation $(p=0.3)$.

The difference in the mean number of sedation and ventilation days between the two groups was not statistically significant (-Table 5). The length of stay in ICU for patients in the extubation failure group was significantly longer (6.8 \pm 1.7 days) compared with that in the extubation success group $(4.8 \pm 1.2$ days $)(p=0.01)$. No mortality occurred in either of the two groups.

The reasons for reintubation in the extubation failure group documented by the ICU in-charge were as follows: severe UAO in 15 (43\%) patients, inability to clear secretions in 12 (34\%) patients, and decrease in GCS by two or more points in 8 (23\%) patients. Among the 35 patients who failed extubation, 17 patients were extubated on the second attempt; 18 patients went on to fail a second extubation trial, out of which 4 patients required a tracheostomy. Patients who required tracheostomy before first extubation trial were not included in the analysis as this was not part of the protocol of our study.

\section{Discussion}

The current study describes the incidence, predictors, and outcomes of extubation failure in pediatric iTBI. We reported an extubation failure rate of $62.5 \%$, which is quite high compared with the previous studies in adult TBI patients that report a failure rate ranging from 16 to $40 \% .^{7,8}$ Extubation failure rates depend on the population being investigated and the definition of extubation failure. These studies did not use a strict time frame for defining extubation failure (e.g., reintubation within 24-72 hours of extubation). However, a study by Kurachek et al reported an incidence of extubation failure as low as $6.2 \%$ in pediatric intensive care. ${ }^{6}$ This study included primarily medical patients with no mention of exclusive head injury patient. Also, the incidence of extubation failure in pediatric patients with iTBI has not been studied so far. Hence, there is a lack of preexisting values to compare the incidence of extubation failure in this particular category of patients.

The success of extubation is influenced by multiple factors. The presenting GCS on hospital admission is one of them. Our study could not find any relationship between extubation failure and the admission GCS ( $p=0.15)$. Our findings could not be compared as there is no definite study on pediatric population to correlate GCS and extubation success. However our study corroborate Coplin et al who conducted a study on 136 adult brain-injured patients and found that 39 of 49 (80\%) patients with GCS $\leq 8$ and 10 of 11 (91\%) patients with a GCS $\leq 4$ were successfully extubated in their study. ${ }^{9}$ This is in contrast to another study of adult neurosurgical patients in which GCS of less than 8 was associated with an increased likelihood of extubation failure. ${ }^{7}$

Our study found that low pre-extubation $\mathrm{paO}_{2} / \mathrm{FiO}_{2}$ ratio of $<310 \mathrm{~mm} \mathrm{Hg}$ was a predictor for extubation failure. This is similar to the findings of previous studies in adult population. ${ }^{10,11}$ However, in several other studies, the $\mathrm{paO}_{2} / \mathrm{FiO}_{2}$ ratio was not significantly associated with extubation outcome. ${ }^{12,13}$ But these studies could not provide a cutoff limit of $\mathrm{paO}_{2} / \mathrm{FiO}_{2}$ ratio, which predicts extubation failure. It is to be mentioned that $\mathrm{paO}_{2} / \mathrm{FiO}_{2}$ ratio of greater than $150 \mathrm{~mm} \mathrm{Hg}$ reflected adequate oxygenation and considered readiness for weaning as per consensus guidelines. ${ }^{13}$

The mean base excess value after extubation was significantly lower in the extubation failure group compared with the extubation success group. Available data are scarce on the effect of acid-base imbalances on clinical outcomes in TBI, even lesser for pediatric TBI. Previous adult studies have demonstrated the effects of initial base excess and blood lactate on predicted mortality in brain trauma patients. ${ }^{14,15}$ Severe TBI profoundly disturbs cerebral acid-base homeostasis, and brain tissue acidosis can cause further neural death. ${ }^{16}$ Acidosis can cause secondary insult to the brain by exacerbation of cerebral edema and further increases the risk of mortality and morbidity. 
Table 3 Univariate analysis and correlation of pre-extubation predictors of extubation failure

\begin{tabular}{|l|l|l|l|l|}
\hline Variable & $\begin{array}{l}\text { Extubation } \\
\text { success }\end{array}$ & $\begin{array}{l}\text { Extubation } \\
\text { failure }\end{array}$ & $p$-Value & $\begin{array}{l}95 \% \mathrm{Cl} \\
\text { (lower-upper) }\end{array}$ \\
\hline $\mathrm{pH}$ & $7.39 \pm 0.03$ & $7.37 \pm 0.03$ & 0.98 & $0.42-0.61$ \\
\hline $\mathrm{paO}_{2} / \mathrm{FiO}_{2}$ ratio & $364.6 \pm 38.7$ & $275.6 \pm 38.7$ & 0.01 & $0.03-0.51$ \\
\hline $\mathrm{paCO}_{2}(\mathrm{~mm} \mathrm{Hg})$ & $36.3 \pm 4.5$ & $36.9 \pm 4.1$ & 0.61 & $1.12-3.38$ \\
\hline Base excess/deficit (mEq/L) & $2.2 \pm 1.3$ & $1.6 \pm 1.5$ & 0.13 & $0.11-0.55$ \\
\hline Lactate (mmol/L) & $1.1 \pm 0.8$ & $0.9 \pm 0.7$ & 0.33 & $0.09-0.49$ \\
\hline Serum sodium level (mEq/L) & $140.2 \pm 4.9$ & $135 \pm 5.3$ & 0.12 & $0.15-6.26$ \\
\hline Serum potassium level (mEq/L) & $3.4 \pm 0.4$ & $3.5 \pm 0.3$ & 0.29 & $0.21-0.62$ \\
\hline Heart rate & $117 \pm 20.2$ & $117.2 \pm 22.0$ & 0.97 & $0.45-2.53$ \\
\hline Systolic blood pressure (mm Hg) & $101.5 \pm 8.5$ & $99.9 \pm 13.7$ & 0.63 & $0.16-0.58$ \\
\hline Albumin level (g/dL) & $3.5 \pm 2.0$ & $3.1 \pm 0.4$ & 0.25 & $0.01-0.31$ \\
\hline Baseline hemoglobin level $(\mathrm{mg} / \mathrm{dL})$ & $10.7 \pm 0.9$ & $9.8 \pm 2.5$ & 0.11 & $0.24-0.67$ \\
\hline Steroid administration & 11 & 19 & 1.00 & $0.23-0.67$ \\
\hline Abbrevion & & \\
\hline
\end{tabular}

Abbreviation: $\mathrm{Cl}$, confidence interval.

Table 4 Univariate analysis and correlation of postextubation predictors of extubation failure

\begin{tabular}{|l|l|l|l|l|}
\hline Variable & $\begin{array}{l}\text { Extubation } \\
\text { success }\end{array}$ & $\begin{array}{l}\text { Extubation } \\
\text { failure }\end{array}$ & $p$-Value & $\begin{array}{l}95 \% \mathrm{Cl} \\
\text { (lower-upper) }\end{array}$ \\
\hline $\mathrm{pH}$ & $7.40 \pm 0.05$ & $7.41 \pm 0.04$ & 0.41 & $0.50-1.61$ \\
\hline $\mathrm{paO}_{2} / \mathrm{FiO}_{2}$ ratio & $361.9 \pm 85$ & $321.2 \pm 85.3$ & 0.08 & $0.30-2.51$ \\
\hline $\mathrm{pCO}_{2}(\mathrm{~mm} \mathrm{Hg})$ & $35.2 \pm 4.9$ & $35.7 \pm 4.9$ & 0.83 & $1.21-5.54$ \\
\hline Base excess/deficit $(\mathrm{mEq} / \mathrm{L})$ & $2.0 \pm 0.9$ & $-0.2 \pm 1.7$ & 0.00 & $0.21-0.95$ \\
\hline Lactate $(\mathrm{mmol} / \mathrm{L})$ & $1.1 \pm 0.6$ & $0.9 \pm 0.7$ & 0.28 & $0.19-1.79$ \\
\hline Serum sodium level $(\mathrm{mEq} / \mathrm{L})$ & $143.2 \pm 6.0$ & $140.2 \pm 8.1$ & 0.14 & $0.66-4.58$ \\
\hline Serum potassium level $(\mathrm{mEq} / \mathrm{L})$ & $3.5 \pm 0.1$ & $3.4 \pm 0.3$ & 0.14 & $2.53-4.62$ \\
\hline Heart rate & $116.7 \pm 20.1$ & $121.5 \pm 17.9$ & 0.35 & $1.13-5.36$ \\
\hline Systolic blood pressure $(\mathrm{mm} \mathrm{Hg)}$ & $100.5 \pm 7.4$ & $113.8 \pm 10.4$ & 0.00 & $0.18-1.98$ \\
\hline Upper airway obstruction & 4 & 12 & 0.06 & $0.37-2.12$ \\
\hline Adrenaline nebulization & 4 & 6 & 0.36 & $0.42-0.97$ \\
\hline
\end{tabular}

Abbreviation: $\mathrm{Cl}$, confidence interval.

Table 5 Comparison of outcomes during the ICU course of patients

\begin{tabular}{|l|l|l|l|}
\hline Parameters (Day) & Extubation success & Extubation failure & $p$-Value \\
\hline Number of sedation & $4.3 \pm 1.8$ & $4.8 \pm 1.0$ & 0.49 \\
\hline Ventilator & $4.5 \pm 1.0$ & $5.8 \pm 1.6$ & 0.07 \\
\hline Length of ICU stay & $4.8 \pm 1.2$ & $6.8 \pm 1.7$ & 0.01 \\
\hline
\end{tabular}

Abbreviation: ICU, intensive care unit.

Note: Values are expressed as mean \pm standard deviation (SD).

A $p$-Value $<0.05$ was taken as statistically significant on comparing between the two groups.

Its utility in prediction of extubation failure has not been studied so far. Our findings demonstrate that metabolic acidosis can be a causative factor in extubation failure in this group of patients.

Increase in postextubation SBP was found to be more in extubation failure patients. This may be due to increased sympathetic stress related to the inadequate respiratory drive. This may also be due to retention of $\mathrm{CO}_{2}$. But in our study both pre- and postextubation $\mathrm{pCO}_{2}$ were comparable with no significant difference.
Extubation failure can result from UAO or due to an inability to manage respiratory secretions, factors that are recognized only after ETT removal. Prolonged intubation, excessive cuff pressures, large or excessively mobile ETTs, and tracheal infection can lead to laryngotracheal trauma in the form of inflammation, granuloma formation, ulceration, or edema. ${ }^{17,18}$ This may lead to glottic or subglottic narrowing and manifest as UAO after extubation. The prerequisites for efficient clearance of respiratory secretions include adequate laryngeal function, intact swallowing function, 
expiratory muscle function, and effective cough. Laryngeal function impairment in critically ill TBI patients may result from impaired neurological status, presence of the nasogastric tube, and the effects of sedative/hypnotic and narcotic agents. ${ }^{18} \mathrm{~A}$ prolonged duration of ventilation increases the incidence of swallowing dysfunction, which may take a week or more to resolve. ${ }^{19,20}$ Multiple causative factors, such as weakness of inspiratory and expiratory muscles, tracheomalacia, glottic incompetence, and narcotic administration, have been identified for ineffective cough. Increased airway secretions can result from ETT irritation, secretions from the naso- or oropharynx, and infectious or noninfectious airway inflammation. $^{21}$

Additional anatomic and physiologic factors may contribute to the high extubation failure rate in the pediatric population. Respiration is less efficient in infants. The chest wall in infants is highly compliant with low elastic recoil and hence are at higher risk of lung collapse with tidal breathing which takes place in the range of the closing capacity of the lung. ${ }^{22}$ The subglottic larynx is the narrowest portion of the infant's airway and is vulnerable to mucosal irritation and inflammatory edema with endotracheal intubation, leading to UAO after extubation. In fact, UAO was the most common reason cited for extubation failure in our study, accounting for $46 \%$ of cases of extubation failure. However, it was not found to be significantly associated with the success rate of extubation $(p=1.00)$.

Previous studies have demonstrated a favorable outcome and hospital mortality rates below 10 to $15 \%$ for patients who tolerate extubation for a minimum of 24 to 72 hours. ${ }^{23}$ On the other hand, ICU and hospital mortality are markedly higher among patients who require reintubation within 24 to 72 hours after extubation. Extubation failure also prolongs the duration of mechanical ventilation, length of ICU and hospital stay, and the need for tracheostomy. ${ }^{5}$ The current study did not demonstrate a significant increase in mortality and duration of mechanical ventilation in the extubation failure group. However, the length of ICU stay was significantly prolonged in the extubation failure group compared with the extubation success group. Among the extubation failure patients, $30.79 \%$ eventually required tracheostomy.

There are several limitations to our study. First, the sample size of the study was small. More number of patients may be needed to allow better comparison and establish a predictive relationship between various factors and extubation failure. Our trauma intensive care was not pediatric specific, and also patients of this age group form a small segment of the overall population having isolated traumatic head injury. Second, the decision to extubate was based on the judgment of the ICU in-charge, which was not blinded. Third, the study did not assess other factors such as the incidence of ventilator-associated pneumonia that could predict extubation failure. Despite its limitations, our study was a first of a kind attempt to find out the incidence, predictors, and their outcomes in extubation failure patient belonging to age group of 0 to 5 years with iTBI.

\section{Conclusion}

Our study found that the incidence of first attempt extubation failure was $62.5 \%$. Low pre-extubation $\mathrm{paO}_{2} / \mathrm{FiO}_{2}$ (ratio $<310 \mathrm{~mm} \mathrm{Hg}$ ) is a predictor for extubation failure. The mean base excess value and increased systolic pressure after extubation was more in the extubation failure group compared with the extubation success group. This leads to increased ICU stay. Developing predictive tools and optimizing extubation decisions require knowledge of the risk factors for predictors of extubation failure. Timely identification of patients at elevated risk of extubation failure may improve ICU outcomes and decrease morbidity and mortality.

\section{Conflict of Interest}

None declared.

\section{Acknowledgment}

The authors acknowledge the contribution of the nursing staff of the trauma ICU.

\section{References}

1 Dewan MC, Mummareddy N, Wellons JC III, Bonfield CM. The epidemiology of global pediatric traumatic brain injury: a qualitative review. World Neurosurg 2016;91:497-509.e1

2 Orlowski JP, Ellis NG, Amin NP, Crumrine RS. Complications of airway intrusion in 100 consecutive cases in a pediatric ICU. Crit Care Med 1980;8(6):324-331

3 Benjamin PK, Thompson JE, O'Rourke PP. Complications of mechanical ventilation in a children's hospital multidisciplinary intensive care unit. Respir Care 1990;35(9):873-878

4 Torres A, Gatell JM, Aznar E, et al. Re-intubation increases the risk of nosocomial pneumonia in patients needing mechanical ventilation. Am J Respir Crit Care Med 1995;152(1):137-141

5 Epstein SK, Ciubotaru RL, Wong JB. Effect of failed extubation on the outcome of mechanical ventilation. Chest 1997;112(1):186-192

6 Kurachek SC, Newth CJ, Quasney MW, et al. Extubation failure in pediatric intensive care: a multiple-center study of risk factors and outcomes. Crit Care Med 2003;31(11):2657-2664

7 Anderson CD, Bartscher JF, Scripko PD, et al. Neurologic examination and extubation outcome in the neurocritical care unit. Neurocrit Care 2011;15(3):490-497

8 Wang S, Zhang L, Huang K, Lin Z, Qiao W, Pan S. Predictors of extubation failure in neurocritical patients identified by a systematic review and meta-analysis. PLoS One 2014;9(12):e112198

9 Coplin WM, Pierson DJ, Cooley KD, Newell DW, Rubenfeld GD. Implications of extubation delay in brain-injured patients meeting standard weaning criteria. Am J Respir Crit Care Med 2000;161(5):1530-1536

10 Namen AM, Ely EW, Tatter SB, et al. Predictors of successful extubation in neurosurgical patients. Am J Respir Crit Care Med 2001;163(3 Pt 1) :658-664

11 Saugel B, Rakette P, Hapfelmeier A, et al. Prediction of extubation failure in medical intensive care unit patients. J Crit Care 2012;27(6):571-577

12 Ko R, Ramos L, Chalela JA. Conventional weaning parameters do not predict extubation failure in neurocritical care patients. Neurocrit Care 2009;10(3):269-273

13 Boles JM, Bion J, Connors A, et al. Weaning from mechanical ventilation. Eur Respir J 2007;29(5):1033-1056

14 Dübendorfer C, Billeter AT, Seifert B, Keel M, Turina M. Serial lactate and admission SOFA scores in trauma: an analysis of 
predictive value in 724 patients with and without traumatic brain injury. Eur J Trauma Emerg Surg 2013;39(1):25-34

15 Jeremitsky E, Omert L, Dunham CM, Protetch J, Rodriguez A. Harbingers of poor outcome the day after severe brain injury: hypothermia, hypoxia, and hypoperfusion. J Trauma 2003;54(2):312-319

16 Clausen T, Khaldi A, Zauner A, et al. Cerebral acid-base homeostasis after severe traumatic brain injury. J Neurosurg 2005;103(4):597-607

17 Ho LI, Harn HJ, Lien TC, Hu PY, Wang JH. Postextubation laryngeal edema in adults. Risk factor evaluation and prevention by hydrocortisone. Intensive Care Med 1996;22(9):933-936

18 Darmon JY, Rauss A, Dreyfuss D, et al. Evaluation of risk factors for laryngeal edema after tracheal extubation in adults and its prevention by dexamethasone. A placebo-controlled, double-blind, multicenter study. Anesthesiology 1992;77 (2):245-251
19 Kastanos N, Estopá Miró R, Marín Perez A, Xaubet Mir A, AgustíVidal A. Laryngotracheal injury due to endotracheal intubation: incidence, evolution, and predisposing factors. A prospective long-term study. Crit Care Med 1983;11(5):362-367

20 de Larminat V, Montravers P, Dureuil B, Desmonts JM. Alteration in swallowing reflex after extubation in intensive care unit patients. Crit Care Med 1995;23(3):486-490

21 Mier A, Laroche C, Agnew JE, et al. Tracheobronchial clearance in patients with bilateral diaphragmatic weakness. Am Rev Respir Dis 1990;142(3):545-548

22 Cote CJ. Pediatric anaesthesia. In: Miller RD, Cohen NH, Erikkson LI, Fleisher LA, Wiener- Kronish JP, Young WL, eds. Miller's Anesthesia. 8th ed. Philadelphia: Elsevier Saunders; 2015: 2757-2796

23 Farias JA, Retta A, Alía I, et al. A comparison of two methods to perform a breathing trial before extubation in pediatric intensive care patients. Intensive Care Med 2001;27(10):1649-1654 